\title{
Estudo Comparativo das Propriedades de Óleo de Coco Obtido pelos Processos Industrial e Artesanal
}

\author{
J akeline Santos Martins* (Graduanda em Química na Universidade Federal de Campina Grande - \\ UFCG); \\ J osé Carlos Oliveira Santos (Professor da UABQ/CES na Universidade Federal de Campina Grande - \\ UFCG) \\ *E-mail: jake-line-martins@hotmail.com
}

\begin{abstract}
Resumo: O óleo de coco (Cocos nucifera L.), muito utilizado pela indústria alimentícia e farmacêutica, tem exigido métodos analíticos capazes de avaliar as condições de processamento e estocagem. Neste trabalho comparou-se a composição química e as propriedades físico-químicas do óleo de coco extra virgem produzido por indústria brasileira e do óleo de coco obtido de forma artesanal (comercializado na feira livre de Cuité - PB). Os resultados obtidos confirmaram o alto teor de ácidos graxos saturados do óleo de coco, em razão, principalmente, do alto conteúdo de ácido láurico (aproximadamente $2 \%$ para o óleo extra virgem e 3\% para o óleo obtido artesanalmente), responsável por aumentar a estabilidade oxidante, além de alterar o perfil de fusão do óleo, contribuindo para o aumento da utilização da gordura deste óleo em produtos específicos das indústrias farmacêutica e alimentícia. Pode se avaliar que na maioria dos casos, os resultados obtidos para as amostras de óleo de coco industrial e artesanal foram mais elevados do que os padrão estabelecidos pela Resolução № 482 , de 23/09/1999, da Agência Nacional da Vigilância Sanitária - ANVISA, onde pode ter efeitos negativos sobre a qualidade do óleo, a ponto de ser impróprio para alimentação humana. O método de extração artesanal pouco interferiu nas propriedades físico-químicas, pois independentes da metodologia adotada estes parâmetros permanecem dentro dos limites estipulados pela legislação vigente para óleos prensados a frio e não refinados. Mas, as análises feitas do óleo de coco foram de extrema importância para podermos referenciar este óleo que seus estudos estão ainda escassos e controversos na literatura. Considerando que o óleo de coco está sendo bastante divulgado pelos meios de comunicação, no que diz respeito às suas propriedades terapêuticas, a análise comparativa da composição química e das características físico-químicas dos óleos estudados pode contribuir de forma significativa para fornecer esclarecimentos sobre a diferença entre os óleos, quando obtidos através dos processos industrial e artesanal, objetivando conscientizar as pessoas na obtenção de um produto de qualidade.
\end{abstract}

Palavras-chave: Óleo de coco; produção artesanal; composição química; alimentação.

Espaço reservado para organização do congresso. 


\section{I ntrodução}

Os óleos vegetais são extraídos de diferentes plantas oleaginosas e utilizados principalmente como fonte de alimento e na produção de cosméticos, lubrificantes, tintas, fármacos, biodiesel, entre outros. Óleos e gorduras são reconhecidos como um nutriente essencial para a dieta animal, constituindo a fonte mais concentrada de energia do gênero alimentício. Os lipídios, biomoléculas que possuem elevada solubilidade em solventes orgânicos e baixa solubilidade em água, são suplementos essenciais de ácidos graxos, precursores de hormônios importantes como as prostaglandinas. Os ácidos graxos são considerados os blocos construtores dos lipídios e constituem cerca de $90 \%$ das gorduras nos alimentos (SANTOS e SOUZA, 2007).

O Coqueiro (Cocos Nucifera L.), originário do Sudeste asiático, foi introduzido no Brasil no ano de 1553, onde se apresenta naturalizado em longas áreas da costa nordestina, proporcionando abundante matéria-prima tanto para as agroindústrias regionais quanto para uso alimentício. O óleo de coco, obtido a partir da polpa do coco fresco maduro (espécie Cocos nucifera L.), é composto por ácidos graxos saturados (mais de $80 \%$ ) e ácidos graxos insaturados. Os ácidos graxos saturados presentes no óleo de coco são: capróico, caprílico, cáprico, láurico, mirístico, palmítico e esteárico; e os insaturados são: oléico e linoléico. O óleo de coco é rico em ácido láurico, com concentração acima de $40 \%$. As gorduras láuricas, caso do óleo de coco, são resistentes a oxidação não enzimática e ao contrário de outros óleos e gorduras apresentam temperatura de fusão baixa e bem definida (24,4 $\left.25,6^{\circ} \mathrm{C}\right)$. As gorduras láuricas são muito usadas na indústria cosmética e alimentícia. Em virtude das suas propriedades físicas e resistência à oxidação são muito empregadas no preparo de gorduras especiais para confeitaria, sorvetes, margarinas e substitutos de manteiga de cacau (MORETTO e FETT, 1986; LAWSON, 1999).

Nos últimos anos, alguns estudos têm mostrado que a gordura de coco é capaz de gerar calor e queimar calorias, favorecendo a perda de peso. O óleo de coco também tem sido indicado para diminuir os triglicérideos e o mau colesterol (LDL), aumentar o bom colesterol (HDL) e por possuir ação antiinflamatória. Além disso, a gordura do óleo de coco leva à normalização dos lipídeos, protege o fígado dos efeitos do álcool e aumenta a resposta imunológica contra diversos microrganismos, sendo também benéfica no combate aos fatores de risco para doenças cardiovasculares. Quando submetido a altas temperaturas, o óleo de coco virgem não perde suas características nutricionais, sendo considerado um óleo estável. É também considerado o mais saudável para cozinhar, não apresentando gordura trans gerada pelo processo de hidrogenação, que está presente em todos os outros óleos de origem vegetal, como os de soja, canola, milho e até o de oliva, que é considerado o óleo mais saudável entre os citados, pois apresenta alto teor de gorduras saturadas (MACHADO et al., 2006).

Os óleos vegetais apresentam diversas aplicações em processos industriais e devido a essas potencialidades, tem aumentado constantemente sua demanda de produção. Este trabalho visa avaliar as propriedades químicas e físico-químicas de amostras de óleo de coco industrial e artesanal, de forma comparativa.

\section{Material e Métodos}

\subsection{Material}

Foram analisadas, em duplicata, amostras de 200 gramas de óleos de coco, sendo uma amostra extravirgem, contida em recipientes apropriados, produzidos por indústria brasileira e disponível no mercado, e outra amostra adquirida na feira-livre de Cuité -PB, produzida por meio artesanal (Figura 1), para comparação dos efeitos dos processos de produção sobre a composição em ácidos graxos e características físicas e químicas dos óleos. As análises foram feitas em ambiente laboratorial e temperatura ambiente. 
Figura 1 - Amostras de óleo de coco

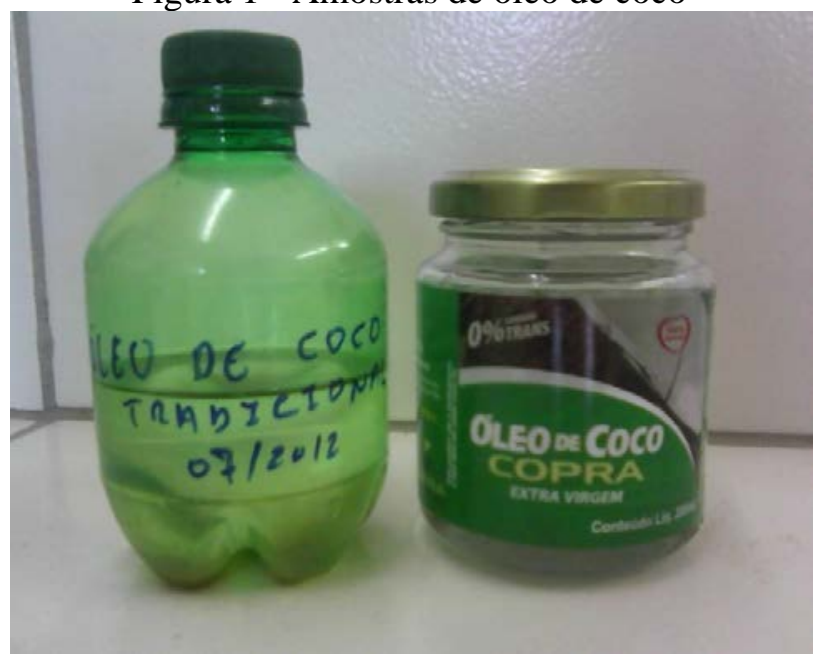

Fonte: Dados da Pesquisa, 2015.

\subsection{Caracterização Química}

As análises de composição em ácidos graxos foram realizadas por cromatografia em fase gasosa dos ésteres metílicos, conforme o método Ce 1-91 da AOCS (1993). A determinação da composição em ácidos graxos por cromatografia gasosa foi realizada sob as seguintes condições:

- Cromatógrafo: HP 5890 série II, com detector de ionização de chama.

- Coluna capilar de sílica fundida de FFAP: $25 \mathrm{~m}$ x 0,2 mm x 0,33 $\mu \mathrm{m}$ i.d.

- Gás de arraste: Hidrogênio analítico 5,0.

- Fluxo do gás de arraste: $1,00 \mathrm{~mL} / \mathrm{min}$.

- Temperatura da coluna: $120^{\circ} \mathrm{C}$ a $210^{\circ} \mathrm{C}$, com programação de $2{ }^{\circ} \mathrm{C} /$ minuto.

- Temperatura do injetor: $250^{\circ} \mathrm{C}$.

- Temperatura do detector: $280^{\circ} \mathrm{C}$.

- Tempo inicial: 1 minuto.

- Tempo final: 32 minutos.

- Pressão na cabeça da coluna: $65 \mathrm{KPa}$

- Taxa de split: $1 / 100$.

A identificação dos ácidos graxos foi realizada por comparação dos tempos de retenção das amostras testes com o tempo de retenção de padrões cromatográficos de ésteres metílicos. A quantificação foi feita pela conversão das porcentagens de áreas dos picos em porcentagem de massa.

\subsection{Caracterização Físico-Química}

As propriedades físico-químicas foram determinadas usando métodos específicos citados na literatura (SANTOS et al., 2006; SANTOS, 2007), sendo realizadas as análises de: pH, solubilidade, índice de acidez, índice de saponificação, índice de iodo, índice de peróxidos, teor de umidade, teor de cinzas e teor de ácidos graxos livre.

\subsubsection{Análise de pH}

$\mathrm{O}$ pH das amostras de óleo de coco foi medido em temperatura ambiente, em um pHmêtro da marca HANNA - Modelo pH 21 pH/mv.

\subsubsection{Solubilidade}

As solubilidades das amostras de óleo de coco foram analisadas, em meio aquoso, alcoólico (etanol) e em éter etílico, a $25^{\circ} \mathrm{C}$. As amostras foram colocadas em béquer de $50 \mathrm{~mL}$, onde foram adicionados os respectivos reagentes para que fosse observada a dissolução das amostras. 


\subsubsection{Determinação da Umidade}

A determinação da umidade foi realizada por método gravimétrico. O procedimento experimental é descrito a seguir: Foram pesados, aproximadamente, $25 \mathrm{~g}$ de areia grossa e colocados em uma cápsula de porcelana de fundo plano contendo um bastão de vidro. Este conjunto de materiais foi seco em estufa a de $105{ }^{\circ} \mathrm{C}$ durante 1 hora e em seguida, resfriado em dessecador, até atingir a temperatura ambiente e poder ser pesado. Logo após a pesagem, colocou-se sobre a areia seca, $10 \mathrm{~mL}$ do óleo de coco de cada amostra a ser analisada e pesou-se novamente, para obtenção da massa da cápsula contendo a amostra úmida.

Com auxílio do bastão de vidro, a amostra do óleo foi misturada com a areia. Esse material foi seco em estufa a $105{ }^{\circ} \mathrm{C}$ durante 2 horas e, em seguida, resfriado em dessecador, até atingir a temperatura ambiente e poder ser pesado, para obtenção da massa da cápsula contendo a amostra seca.

$$
\% \mathrm{H}_{2} \mathrm{O}=\frac{[\text { Cápsula }+ \text { amostra úmida }]-[\text { Cápsula }+ \text { amostra seca }] \times 100}{[\text { Cápsula }+ \text { amostra úmida }]-[\text { tara da cápsula }]}
$$

\subsubsection{Determinação do Í ndice de Acidez}

No procedimento para determinação do índice de acidez, em um erlenmeyer de $250 \mathrm{ml}$ previamente tarado, adicionou- se 2,01g de óleo de coco. Em seguida adicionou-se à mistura de 16,6 ml de éter etílico e $8,3 \mathrm{ml}$ de álcool etílico (2+1) e agitou-se até completa dissolução da amostra. Logo após adicionou 2 gotas de fenolftaleína e 1 gota de hidróxido de potássio $(\mathrm{KOH})$ e titulou-se com solução previamente padronizada de $\mathrm{KOH} 0,1 \mathrm{~mol} / \mathrm{l}$, até o aparecimento de uma coloração levemente rósea. Para calcular o índice de acidez, expressando o resultado em $\mathrm{mg} \mathrm{KOH/g} \mathrm{de} \mathrm{óleo,} \mathrm{utilizou-se} \mathrm{a} \mathrm{seguinte}$ equação:

$$
\text { Índice de acidez (mg KOH/g de óleo) }=\frac{\mathrm{V} \times \mathrm{M} \text { x 56,1 }}{\mathrm{P}}
$$

em que: $\mathrm{V}$ = volume da solução de $\mathrm{KOH}$ gastos na titulação em $\mathrm{mL} ; \mathrm{M}=$ Molaridade da solução de $\mathrm{KOH} ; \mathrm{P}=$ número de gramas da amostra.

\subsubsection{Determinação do Í ndice de Saponificação}

O índice de saponificação foi determinado, colocando-se $2 \mathrm{~g}$ de óleo de coco em um balão de fundo chato de $250 \mathrm{~mL}$, previamente tarado. Em seguida, adicionou-se $25 \mathrm{~mL}$ de solução alcoólica de hidróxido de potássio $(\mathrm{KOH})$ agitando para a completa dissolução da amostra. Em outro balão de fundo chato de $250 \mathrm{~mL}$ colocou-se $25 \mathrm{~mL}$ de $\mathrm{KOH}$ para fazer a prova em branco. Em seguida, os balões foram adaptados aos condensadores de refluxo e aquecidos em banho-maria durante 30 minutos. A cada 5 minutos agitou-se a solução para que houvesse uma melhor dissolução da amostra. Ao retirar do banho-maria, titulou-se com ácido clorídrico $1 \mathrm{~mol} / \mathrm{l}(\mathrm{HCl})$ até descoramento da fenolftaleína. Para calcular o índice de saponificação, expressando o resultado em mg de $\mathrm{KOH} / \mathrm{g}$ de óleo, utilizou-se a seguinte equação:

$$
\text { Índice de saponificação }\left(\mathrm{mg} \frac{\mathrm{KOH}}{\mathrm{g}} \text { de óleo }\right)=\frac{\mathrm{V} \times \mathrm{N} \times \mathrm{F} \times 56,1}{\mathrm{P}}
$$

em que: $\mathrm{V}$ = diferença entre o volume de $\mathrm{HCl}$ em $\mathrm{mL}$, gasto na titulação com a amostra e o volume de $\mathrm{HCl}$ em mL, gasto na titulação do branco; $\mathrm{F}$ = fator de correção na padronização do ácido clorídrico; $\mathrm{P}$ = massa da amostra em gramas; $\mathrm{N}$ = normalidade da solução;56,1 = peso molecular do KOH.

\subsubsection{Aparência}

A aparência dos óleos de coco foi analisada visualmente, com o intuito de observar a presença de impurezas.

\subsubsection{Determinação do Í ndice de I odo}

Na determinação do índice de iodo, em um erlenmeyer de $250 \mathrm{~mL}$ previamente tarado, colocou-se 0,30 mL do óleo de coco e pesou-se. Em seguida, adicionou-se $15 \mathrm{~mL}$ de clorofórmio e agitou-se até a 
completa dissolução da amostra. Depois adicionou-se $25 \mathrm{~mL}$ do Reativo de Rubl. Deixou-se a amostra em um local escuro por 4 horas. Depois adicionou-se $15 \mathrm{~mL}$ de iodeto de potássio (KI a 10\%) e 100 $\mathrm{mL}$ de água destilada. Em seguida, titulou-se o excesso de iodo com tiossulfato de sódio em presença de amido. Anotou-se o volume gasto e calculou-se o índice de iodo do óleo de coco expressando o resultado em g de iodo/100g do óleo. Fez paralelamente uma prova em branco. Para determinar o índice de iodo do óleo de coco usou-se a seguinte equação:

$$
\text { índice de iodo }\left(g \frac{\text { iodo }}{100 g} \text { óleo }\right)=\frac{\mathrm{V} \times \mathrm{F} \text {. equivalente } \mathrm{x} 100}{\mathrm{P}}
$$

em que: $\mathrm{V}=$ diferença entre os números de $\mathrm{mL}$ de solução de tiossulfato de sódio 2,5\% gastos nas titulações; $\mathrm{F}$ = fator da solução de tiossulfato de sódio $0,5 \%$ e $\mathrm{P}=$ número de g da amostra.

\subsubsection{Teor de Cinzas}

O teor de cinzas foi determinado colocando-se uma cápsula de porcelana em uma mufla marca QUIMIS, a uma temperatura de $600^{\circ} \mathrm{C}$, por 20 minutos, colocando-se em seguida para esfriar. Quando foi atingida a temperatura ambiente, adicionou-se 2,0 g de óleo de coco e pesou-se. Logo após colocou-se o conjunto na mufla, a $600^{\circ} \mathrm{C}$, por um período de $4 \mathrm{~h}$. Após a amostra esfriar, pesou-se novamente. Para a determinação de cinzas do óleo dos óleos de coco, usou-se a seguinte equação:

$$
\text { Cinzas } \%=\frac{(\text { Peso cápsula com amostra seca })-(\text { Peso da cápsula }) \times 100}{\text { Peso da amostra }}
$$

\subsubsection{Densidade}

Para obtenção da densidade, em uma proveta de $25 \mathrm{ml}$ previamente tarada, colocou-se $10 \mathrm{ml}$ de óleo na proveta previamente tarado e pesou-se em uma balança marca DIGMED, modelo DG-2000 e anotou-se o peso. Para a determinação das densidades das amostras de óleo de coco usou-se a seguinte equação:

$$
\mathrm{D}=\frac{\text { Peso da amostra }(\mathrm{g})}{\text { Volume da amostra }(\mathrm{ml})}
$$

\subsubsection{Teor de Ácidos Graxos Livres}

O teor de ácidos graxos livres, expresso em percentagem de ácido láurico, foi determinado adicionando-se 2,01g de óleo de coco em um erlenmeyer de $250 \mathrm{ml}$ previamente tarado. Em seguida adicionou-se a mistura de 16,6 ml de éter e 8,3 ml de álcool (2+1) e agitou-se até completar dissolução da amostra. Logo após adicionou duas gotas de fenolftaleína e um gota de $\mathrm{KOH}$ e titulou-se com hidróxido de potássio (KOH 0,1 mol, padrão) até o aparecimento de uma coloração rósea transparente. Para calcular o índice de acido láurico utilizou-se a seguinte equação:

$$
\% \text { ácido láurico }=\frac{\mathrm{V} \times \mathrm{N} \times 200}{\mathrm{P}}
$$

em que $\mathrm{V}=$ Número de $\mathrm{mL}$ de solução de $\mathrm{KOH}$ gasto na titulação; $\mathrm{N}=$ Normalidade da solução de $\mathrm{KOH}$; P = Número de gramas de amostra e 200 = Fator de ácido láurico.

\subsubsection{Determinação do Índice de Peróxidos}

Na determinação do índice de peróxido, em um erlenmeyer de $250 \mathrm{~mL}$ previamente tarado, colocou-se $1 \mathrm{~g}$ da amostra de óleo de coco. Logo após adicionou-se $20 \mathrm{~mL}$ da solução de ácido acéticoclorofórmio 3:2, agitando-os até dissolver completamente a amostra. Em seguida, adicionou-se 0,5 mL de KI e intercala três agitações em 1 min de repouso, ao final do procedimento, imediatamente, colocou-se $10 \mathrm{~mL}$ de água destilada. Depois, titula-se lentamente a solução de $\mathrm{Na}_{2} \mathrm{~S}_{2} \mathrm{O}_{3}$ sob constante agitação magnética, até que a cor amarela desapareça quase totalmente, e adicionam-se $2 \mathrm{~mL}$ da solução de amido para continuar a titulação, sob agitação, até que a cor azul desapareça, liberando todo iodo da camada do solvente. Para determinar o índice de peróxido das amostras de óleo de coco usou-se a seguinte equação: 


$$
\text { I. P. }=\frac{(\mathrm{Vb}-\mathrm{Va}) \times \mathrm{C} \times \mathrm{F} \times 1000}{\mathrm{~m}}
$$

onde: I.P. = índice de peróxido (mEq de peróxido/1.000 g de amostra); $\mathrm{Va}=$ volume $(\mathrm{mL})$ da solução de $\mathrm{Na}_{2} \mathrm{~S}_{2} \mathrm{O}_{3}$ 0,01 mol/L gasto na titulação da amostra; $\mathrm{Vb}=$ volume $(\mathrm{mL})$ da solução de $\mathrm{Na}_{2} \mathrm{~S}_{2} \mathrm{O}_{3} 0,01$ $\mathrm{mol} / \mathrm{L}$ gasto na titulação da prova em branco; $\mathrm{C}=$ concentração molar da solução de $\mathrm{Na}_{2} \mathrm{~S}_{2} \mathrm{O}_{3}$ igual a $0,01 \mathrm{~mol} / \mathrm{L} ; \mathrm{F}$ = fator de correção da solução de $\mathrm{Na}_{2} \mathrm{~S}_{2} \mathrm{O}_{3}$ 0,01 mol/L; $\mathrm{m}=$ massa da amostra (g).

\section{Resultados e Discussão}

O óleo de coco é considerado uma exceção quando comparado com outros óleos vegetais, pois apesar de ser altamente saturado, é liquido, devido à predominância de ácidos graxos de cadeia média (AGCM), que correspondem a 70-80\% de sua composição. O fato do óleo de coco possuir maior quantidade de AGCM, diferentemente de outras gorduras saturadas, faz com que tenha um comportamento metabólico distinto em virtude de suas características estruturais.

A composição em ácidos graxos dos óleos analisados encontra-se listada na Tabela 1.

Tabela 1- Composição em ácidos graxos (\% 100g) do óleo de coco.

\begin{tabular}{l|cc}
\hline \multirow{2}{*}{ Ácidos graxos } & \multicolumn{2}{|c}{ Teor de ácidos graxos (\%) } \\
\cline { 2 - 3 } & Óleo de coco extra virgem & Óleo de coco artesanal \\
\hline Ácido capróico & 0,38 & 0,30 \\
Ácido caprílico & 5,56 & 6,64 \\
Ácido cáprico & 4,99 & 6,00 \\
Ácido laúrico & 45,78 & 47,13 \\
Ácido mirístico & 18,56 & 18,60 \\
Ácido palmítico & 8,85 & 8,70 \\
Ácido esteárico & 3,39 & 2,59 \\
Ácido oléico & 5,65 & 7,70 \\
Ácido linoléico & 0,94 & 1,34 \\
\hline
\end{tabular}

Os resultados confirmam o alto teor de ácidos graxos saturados do óleo de coco, em razão, principalmente, do alto conteúdo de ácido láurico, que aliada à hidrogenação pode aumentar a estabilidade oxidativa do produto, além de alterar o ponto de fusão, aumentando a gama de utilização destas gorduras em produtos específicos. Os óleos vegetais ao serem submetidos à hidrogenação para adquirir as características de fusão e estabilidade necessárias para elaboração de sorvetes estão sujeitos ao aparecimento de novos tipos de compostos, entre eles os isômeros trans. A formação de isômeros trans durante a hidrogenação parcial dos óleos vegetais é proporcional à formação de condições drásticas de processamento, como altas temperaturas. Em termos nutricionais os isômeros trans são digeridos, absorvidos e incorporados pelo organismo de modo similar aos isômeros cis, porém, não apresentam atividade como ácidos graxos essenciais. Há alguns aspectos ainda não totalmente elucidados quanto à influência dos isômeros trans em alguns tipos de câncer, aterosclerose e outros problemas de saúde (KAWASHIMA e SOARES, 1993).

No estabelecimento dos parâmetros de qualidade para aceitabilidade de óleos vegetais é importante que os valores para o índice de acidez sejam os menores possíveis, uma vez que elevados valores são indicativos de alterações pronunciadas, comprometendo a capacidade de utilização dos mesmos, sejam para fins alimentícios ou carburantes. Os parâmetros físico-químicos avaliados para as amostras de óleos de coco analisadas neste trabalho estão listados na Tabela 2.

O monitoramento da acidez dos óleos vegetais também é usado como método auxiliar durante as fases de processamento, estocagem e controle de qualidade dos mesmos (SANTOS, 2007). O índice de acidez revela o estado de conservação do óleo, expresso como número de miligramas de hidróxido de potássio necessário para neutralizar os ácidos livres de um grama da amostra. O índice de acidez elevado indica, portanto, que o óleo está sofrendo quebras em sua cadeia, liberando seus constituintes principais, os ácidos graxos livres. O cálculo desse índice é de extrema importância na avaliação do estado de deterioração do óleo que são fornecidos para consumo. Por meio desse método, pode-se determinar se o óleo sofreu rancificação hidrolítica ou oxidativa. 
Tabela 2 - Parâmetros físico-químicos das amostras de óleo de coco.

\begin{tabular}{llll}
\hline \multicolumn{1}{c}{ Análises } & $\begin{array}{c}\text { Amostra de óleo } \\
\text { de coco } \\
\text { extra virgem }\end{array}$ & $\begin{array}{c}\text { Amostra de } \\
\text { óleo de coco } \\
\text { artesanal }\end{array}$ & $\begin{array}{c}\text { Padrão para o } \\
\text { óleo de coco }\end{array}$ \\
\hline Aspecto & $\begin{array}{l}\text { Límpido, sem } \\
\text { impurezas }\end{array}$ & $\begin{array}{l}\text { Límpido, sem } \\
\text { impurezas } \\
\text { Cinzas (\%) }\end{array}$ & $\begin{array}{l}\text { Límpido, sem } \\
\text { impurezas }\end{array}$ \\
Densidade & 0,005 & 0,005 & - \\
& 0,897 & 0,896 & $0,903-0,924$ \\
Índice de Acidez (mg KOH/g óleo) & 0,558 & 0,837 & $0,3<$ (bruto); \\
& & & $0,5<$ (refinado) \\
\% ácido láurico & 1,990 & 2,985 & $0,5 \%<$ \\
Índice de Iodo & 15 & 21 & $14-23$ \\
Índice de Saponificação (mg KOH/g óleo) & 222 & 233 & $247-255$ \\
Umidade (\%H $\left.{ }_{2} \mathrm{O}\right)$ & 0,263 & 0,382 & - \\
pH & 3,33 & 3,50 & - \\
Índice de peróxido & 0,959 & 2,158 & - \\
\hline
\end{tabular}

Os valores médios de acidez determinados nas amostras encontraram-se abaixo do valor máximo estabelecido para óleos brutos (4,0 mg KOH/g de óleo). Esses resultados demonstram que não ocorreram hidrólise e oxidação dos lipídeos durante a produção e armazenamento do óleo e que, provavelmente, a temperatura ambiente e as condições de armazenamento nas quais as amostras se encontravam não afetaram sobremaneira os ácidos graxos constituintes, sendo comprovada pela acidez dos óleos dentro dos padrões de conformidade. O índice de acidez da amostra do óleo de coco extraído artesanalmente, entretanto, se mostrou superior em relação a amostra do óleo de coco industrial, conforme se verifica na Tabela 2. Comumente, o índice de acidez pode revelar formas incorretas de colheita dos frutos, amadurecimento e armazenamento impróprios, além de processos insatisfatórios de extração. Além disso, a decomposição das gorduras pela enzima lipase é acelerada pela luz e calor, com formação de ácidos graxos livres (AGL) que aumentam a acidez e causam sabor e odor desagradáveis (LIMA et al., 2008). Portanto, o valor da acidez mais elevado numa amostra pode ser um indicativo de início de desenvolvimento de reações hidrolíticas. Aliado a isso, o armazenamento do óleo, feito em embalagens PET sem a proteção adequada contra a passagem de luz, contribui para a diminuição da sua estabilidade, pois a amostra de óleo de coco extraído artesanalmente pode ter permanecido, durante o período de seu armazenamento, mais exposta à luz e, portanto, ter sofrido maior alteração no teor ácidos graxos em relação à outra amostra. Diante do exposto, pode-se observar que, de modo geral, os índices de acidez do óleo de coco apresentaram resultados positivos, indicando bom estado inicial de conservação, e que, apesar das condições adversas de armazenamento, essas não foram suficientemente agressivas para a deterioração dos óleos segundo os limites de aceitabilidade explicitados na legislação.

O índice de iodo é um parâmetro usado para prever a presença de duplas ligações em um éster de ácido graxo. Quanto maior o valor encontrado para este índice, maior o grau de insaturação, servindo como indicativo de tendência à oxidação dos óleos vegetais. Os valores descritos na literatura para o índice de iodo são em geral apresentados como uma faixa de valor, ao invés de um número fixo, porque o grau de insaturação pode variar de acordo com aspectos ligados a sazonalidade da oleaginosa ou em função de diferentes tipos de processamentos do óleo.

A determinação do índice de peróxido em óleos vegetais, pois servirá como estimativa do grau de degradabilidade da matéria-prima. A presença de peróxidos não é desejável em óleos e gorduras, pois pressupõe processos degradativos. Mesmo assim, a Resolução ANVISA nº 482/1999, estabelece valores limites para alguns óleos comestíveis, sendo considerados bons para o consumo aqueles que apresentem um valor máximo de $10 \mathrm{meq} / \mathrm{Kg}$ de óleo ou gordura, a exemplo dos óleos de amendoim, 
linhaça, babaçu, dendê, semente de uva, dentre outros. Alterações nas características sensoriais dos óleos vegetais são em geral atribuídas à presença de peróxidos na matéria graxa. Também podem promover alteração da viscosidade, uma vez que participam das reações de oxidação, que terminam por formar compostos relacionados ao aumento deste parâmetro, a exemplo dos polímeros (MORETTO e FETT, 1989).

Índice de saponificação é a quantidade de base necessária para saponificar definida quantidade de óleo e/ou gordura. É expresso em número de miligramas de hidróxido de potássio necessário para saponificar um grama da amostra. O índice de saponificação é uma indicação da quantidade relativa de ácidos graxos de alto e baixo peso molecular e não serve para identificar o óleo, pois muitos óleos possuem estes índices muito semelhantes (188-196).

Os valores dos índices de saponificação obtidos nas amostras analisadas, se apresentaram abaixo dos limites determinados pela ANVISA (BRASIL, 1999) para o óleo de coco, como apresentado na Tabela 2. Esses resultados demonstram a elevada proporção de ácidos graxos de baixo peso molecular, mas comprovam a semelhança entre diferentes óleos analisados em relação à composição de ácidos graxos.

Os resultados encontrados podem ser explicados considerando a ocorrência de uma variação na natureza dos seus ácidos graxos constituintes ou mesmo de possíveis adulterações com a adição de outros tipos de óleos vegetais com índices de saponificação diferentes. As variações entre os resultados do índice de saponificação podem ser atribuídas também, às características particulares de cada óleo, como a forma de cultivar e a região de cultivo. Outro fator que deve ser levado em consideração é a dificuldade encontrada em saponificar algumas amostras, por necessitarem de mais tempo para o processo.

O teor de cinzas em alimentos refere-se ao resíduo inorgânico, ou resíduo mineral fixo (sódio, potássio, magnésio, cálcio, ferro, fósforo, cobre, cloreto, alumínio, zinco, manganês e outros compostos minerais) remanescente da queima da matéria orgânica em mufla a altas temperaturas (500$600^{\circ} \mathrm{C}$ ) (SANTOS et al., 2004). Nem sempre este resíduo representa toda a substância inorgânica presente na amostra, pois alguns sais podem sofrer redução ou volatilização quando aquecidos em temperaturas altas (SANTOS et al., 2007). A Tabela 2 mostra os resultados da quantidade de cinza nessas amostras de óleos. Pode-se concluir que as matérias consideradas insolúveis totais obtidas nas determinações de insolúveis no éter são de origem orgânica, uma vez que, após a queima em mufla a $550^{\circ} \mathrm{C}$, não foi obtido teor de cinzas nas amostras de óleo de coco investigadas. Não foram encontrados na literatura valores para os limites mínimos para a determinação do teor de cinzas em óleo de coco.

Durante o processo de refino de óleos comestíveis têm-se a preocupação de eliminar ao máximo a umidade adquirida em algumas fases do processo, com a finalidade de preservar as características do produto final por um longo período de tempo. A presença da umidade nos óleos e o calor favorecem a ativação de enzimas que hidrolisam rapidamente o óleo, produzindo um aumento considerável da acidez livre gerando um odor e sabor desagradável de ranço. Além destas condições também perdem componentes alimentícios valiosos como vitaminas e antioxidantes (SANTOS et al., 2007).

O índice de iodo é a medida de insaturações em óleos e gorduras e é utilizado como controle de alguns processamentos. Esse índice é baseado no fato de que o iodo e outros halogênios se adicionam numa dupla ligação da cadeia insaturada dos ácidos graxos e expresso em número de gramas de iodo absorvido por $100 \mathrm{~g}$ da amostra.

A Tabela 3 mostra a solubilidade do óleo de coco em diferentes solventes.

Tabela 3 - Solubilidade das amostras de óleo de coco.

\begin{tabular}{cccc}
\hline Amostras de óleo de coco & Água & Álcool Etílico & Éter Etílico \\
\hline Extra virgem & Insolúvel & Insolúvel & Solúvel \\
Feira Livre & Insolúvel & Insolúvel & Solúvel \\
\hline \multicolumn{4}{c}{ Fonte: Dados da Pesquisa, 2015. }
\end{tabular}

Na Figura 2, é possível observar o teste da solubilidade das amostras de óleo de coco utilizando os três tipos de solventes: água, álcool etílico e éter etílico, nas proporções de 1:1 (amostra/solvente). Em meio aquoso, como já era de se esperar, as amostras de óleo de coco não se 
misturaram com a água, mesmo com agitação constante, pois os óleos e as gorduras são substâncias apolares e a água é polar. Em meio alcoólico as amostras de óleo de coco não se misturaram com o álcool. As amostras de óleo de coco apresentaram solubilidade total em meio com éter etílico.

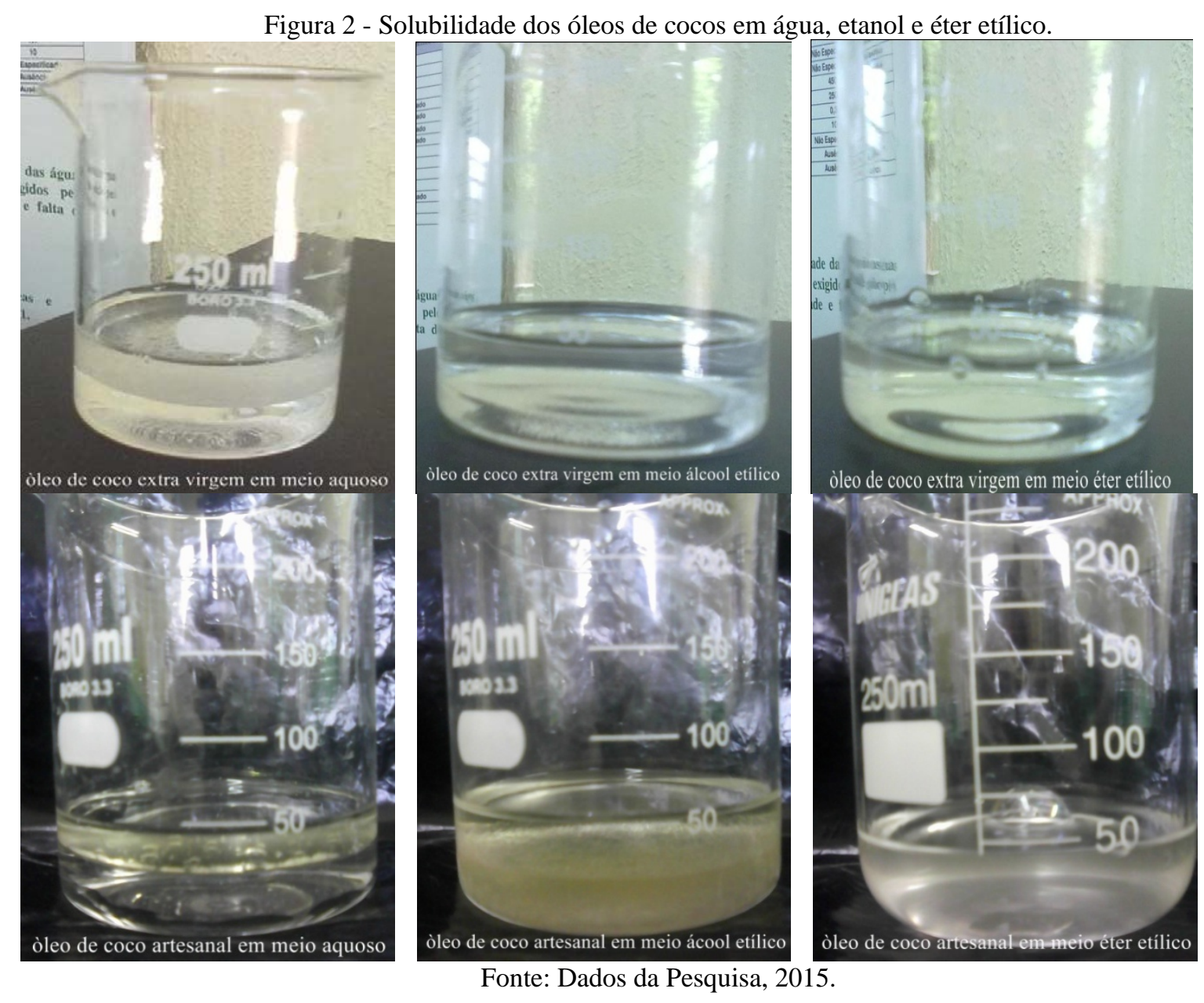

\section{Conclusões}

Pode se avaliar que na maioria dos casos, os resultados obtidos para as amostras de óleo de coco industrial e artesanal foram mais elevados do que os padrão estabelecidos pela Resolução $\mathrm{N}^{0} 482$, de 23/09/1999, da Agência Nacional da Vigilância Sanitária - ANVISA, onde pode ter efeitos negativos sobre a qualidade do óleo, a ponto de ser impróprio para alimentação humana.

O método de extração artesanal pouco interfere nas propriedades físico-químicas, pois independentes da metodologia adotada estes parâmetros permanecem dentro dos limites estipulados pela legislação vigente para óleos prensados a frio e não refinados. Mas, as análises feitas do óleo de coco foram de extrema importância para podermos referenciar este óleo que seus estudos estão ainda escassos e controversos na literatura.

É importante salientar que o óleo de coco é denominado como extra virgem pelo fato de possuir um índice de acidez inferior a 0,5\%. Além disso, o teor de gordura saturada do óleo de coco é semelhante ao do leite humano, o que significa que ela é de fácil digestão, gerando energia rapidamente e efeito benéfico sobre o sistema imunológico. 


\section{Comparative Study of Coconut Oil Properties}

Abstract: Coconut oil (Cocos nucifera $L$.), widely used by the food and pharmaceutical industries, has required analytical methods to assess the conditions of processing and storage. This paper compared the chemical composition and physical-chemical properties of extra virgin coconut oil produced by Brazilian industry and coconut oil obtained by hand (marketed in the free fair Cuité - PB). The results confirmed the high content of saturated fatty acids of coconut oil, due mainly to the high content of lauric acid (approximately 2\% for the extra virgin oil and 3\% for oil obtained by hand), responsible for increasing the oxidative stability, as well as change the profile oil merger, contributing to the increased use of fat of this oil in specific products of the pharmaceutical and food industries. It may be appreciated that in most cases, the results for the industrial and artisanal coconut oil samples were higher than the standard established by Resolution $N^{\circ} 482$ of 09.23.1999, the National Health Surveillance Agency - ANVISA where you can have negative effects on oil quality as to be unfit for human consumption. The artisanal extraction method slightly interfered with physicochemical properties as independent of the methodology used these parameters remain within the limits stipulated by law for cold pressed oils and unrefined. But the analyzes of coconut oil were extremely important for us to refer to the oil that his studies are still scarce and controversial in the literature. Considering that coconut oil is being widely publicized by the media, with regard to their therapeutic properties, the comparative analysis of the chemical composition and physical and chemical characteristics of the studied oils can contribute significantly to provide clarification on the difference between oils when obtained through the industrial and artisanal processes, aiming to raise awareness in getting a quality product.

Keywords: Coconut oil; craft production; chemical composition; food.

\section{Referências}

AOCS (American Oil Chemists' Society) Official methods and recommended practices of the American Oil Chemists' Society. Champaign: AOCS, 1993.

BRASIL. Ministério da Saúde: Agência Nacional de Vigilância Sanitária (ANVISA). 1999. Resolução RDC $n^{\circ}$ 482, de 23 de setembro de 1999. Aprova o Regulamento Técnico: "Fixação de I dentidade e Qualidade de Óleos e Gorduras Vegetais". Disponível em: <http://www.anvisa.gov.br/>. Acesso em: dia de mês, ano. Acesso em 15 de outubro de 2015.

KAWASHIMA, L. M; SOARES, L. M. V. Gordura em sorvetes nacionais: conteúdo, composição de ácidos graxos e teor de trans-isomeros. Ciência e Tecnologia de Alimentos, 13, 2, 1993.

LAWSON, H. Aceites y grasas alimentarios: tecnología, utilización y nutrición. Acribia, 1999.

LIMA, L. N.; CARVALHO, M. W. N.; SANTOS, J. C. O. Caracterização Térmica e Oxidativa do Biodiesel Derivado do Óleo de Algodão. Química no Brasil, V. 2, p. 91-96, 2008.

MACHADO, G. C.; CHAVES, J. B. P.; ANTONIASSI, R. Composição em ácidos graxos e caracterização física e química de óleos hidrogenados de coco babaçu. Revista Ceres, 53 (308), 463, 2006.

MORETTO, E.; FETT, R. Óleos e gorduras vegetais: processamento e análises. UFSC, Florianópolis, 1986.

SANTOS, J. C. O.; TRINDADE, M. F. S.; SOUZA, A. G. Thermoanalytical, kinetic and rheological parameters of commercial edible vegetable oils. Journal of Thermal Analysis and Calorimetry, 75, 2, 2004.

SANTOS, J. C. O. Thermal Characterization of the Favelone Oil (Cnidoscolus phyllacanthus). J ournal of Food Technology (Faisalabad), v. 5, p. 77-78, 2007.

SANTOS, J. C. O.; SOUZA, A. G. Thermal Stability of Edible Oils by Thermal Analysis. J ournal of Food Technology (Faisalabad), v. 5, p. 79-81, 2007.

SANTOS, J. C. O.; SOUZA, A. G.; PRASAD, S. Influence of Artificial Antioxidants on Thermal and Oxidative Stability of the Rice Bran Oils Using Thermogravimetry and Differential Scanning Calorimetry. Chemical Technology - An I nidian J ournal, v. 1, p. 2-12, 2006. 
